\title{
A Minority of Patients with Type 1 Diabetes Routinely Downloads and Retrospectively Reviews Device Data
}

\author{
Jenise C. Wong, MD, PhD, Aaron B. Neinstein, MD, ${ }^{2}$ \\ Matthew Spindler, BA, and Saleh Adi, MD ${ }^{1}$
}

\begin{abstract}
Background: In type 1 diabetes (T1D), periodic review of blood glucose and insulin dosing should be performed, but it is not known how often patients review these data on their own. We describe the proportion of patients with T1D who routinely downloaded and reviewed their data at home.

Materials and Methods: A cross-sectional survey of 155 adults and 185 caregivers of children with T1D at a single academic institution was performed. "Routine Downloaders" (downloaded four or more times in the past year) were also considered "Routine Reviewers" if they reviewed their data most of the time they downloaded from devices. Logistic regression was used to identify factors associated with being a Routine Reviewer.

Results: Only $31 \%$ of adults and 56\% of caregivers reported ever downloading data from one or more devices, whereas $20 \%$ and $40 \%$, respectively, were considered Routine Downloaders. Only $12 \%$ of adults and $27 \%$ of caregivers were Routine Reviewers. Mean hemoglobin A1c was lower in Routine Reviewers compared with nonRoutine Reviewers $(7.2 \pm 1.0 \%$ vs. $8.1 \pm 1.6 \%[P=0.03]$ in adults and $7.8 \pm 1.4 \%$ vs. $8.6 \pm 1.7 \%[P=0.001]$ in children). In adjusted analysis of adults, the odds ratio of being a Routine Reviewer of one or more devices for every 10-year increase in age was 1.5 (95\% confidence interval, 1.1, $2.1[P=0.02])$. For every 10 years since diabetes diagnosis, the odds ratio of being a Routine Reviewer was 1.7 (95\% confidence interval, 1.2, $2.4[P=0.01]$ ). For caregivers, there were no statistically significant factors associated with being a Routine Reviewer.

Conclusions: A minority of T1D patients routinely downloads and reviews data from their devices on their own. Further research is needed to understand obstacles, provide better education and tools for self-review, and determine if patient self-review is associated with improved glycemic control.
\end{abstract}

\section{Introduction}

$\mathbf{F}$ OR PATIENTS WITH TYPE 1 diabetes (T1D), optimal glycemic control requires intensive insulin management to prevent short- and long-term complications. ${ }^{1-3}$ Flexible intensive insulin therapy, shown to improve quality of life and glycemic control, requires adjustment of insulin doses based on current blood glucose level and carbohydrate intake and encourages regular review of past data to inform changes in carbohydrate ratios and insulin sensitivity factors. ${ }^{4-6}$ These ratios and factors must be optimized for each patient and should be evaluated and adjusted frequently as insulin requirements change. ${ }^{7,8}$

Blood glucose meters (BGMs), insulin pumps, and continuous glucose monitoring (CGM) have made the real-time process of calculating and dosing insulin easier by facilitating the collection of blood glucose and carbohydrate data and suggesting doses with bolus calculators. ${ }^{9}$ In addition, these

\footnotetext{
${ }^{1}$ Division of Endocrinology, Department of Pediatrics and the Madison Clinic for Pediatric Diabetes, University of California San Francisco, San Francisco, California.

${ }^{2}$ Division of Endocrinology and Metabolism, Department of Medicine and Center for Digital Health Innovation, University of California San Francisco, San Francisco, California.

(C) The Author(s) 2015; Published by Mary Ann Liebert, Inc. This Open Access article is distributed under the terms of the Creative Commons Attribution Noncommercial License (http://creativecommons.org/licenses/by-nc/4.0/) which permits any noncommercial use, distribution, and reproduction in any medium, provided the original author(s) and the source are credited.
} 
diabetes devices have automated the process of recording blood glucose levels, carbohydrate equivalents, and insulin doses, thus reducing the barrier of manual record-keeping and making data more readily available for retrospective review. Currently, proprietary software is required for patients at home, or their providers in the clinic, to download information from the devices and display the data. ${ }^{10-12}$ Regular retrospective review of diabetes data is necessary to adjust insulin regimens and to evaluate the effects of physical activity, other medications, or dietary changes. ${ }^{13-18}$

Despite the importance of retrospectively reviewing diabetes data, most studies have focused on data review by healthcare providers and not by patients themselves. ${ }^{12,19-21}$ The few studies that have described patient download of their own data suggest that patients use retrospective functions of their devices less often than they do real-time functions. ${ }^{22,23}$ In a study of insulin pumps, patients who were instructed to download their pump data weekly did so only 2.2 times/ month; it was not reported whether patients reviewed the retrospective data summaries on their own. ${ }^{24}$ In another study, pump users were asked to download data monthly, but only half the participants downloaded three or more times in a 4-month period. ${ }^{12}$ In the T1D Exchange Clinic Registry, users of CGM found the real-time functions of CGM more useful than the retrospective functions, with many users never downloading data from their CGM device. ${ }^{23}$ Only $27 \%$ of participants reported downloading data from their CGM device at least monthly, and $\leq 15 \%$ did this weekly. ${ }^{23}$

In clinical practice, a patient might download device data to his or her computer and then send or give access to the data to their diabetes provider for guidance, without reviewing the information him- or herself. This might be due to lack of time or uncertainty about what to do with the downloaded information. Alternatively, a patient might review the data on his or her own to help him or her adjust the insulin regimen or daily routine, either with or without the help of a provider. To our knowledge, no studies have specifically described the frequency of retrospective self-review of device data by patients at home. Although diabetes providers often use past device data to recommend changes in insulin regimens, it is not known if patients use or find value in downloading and reviewing device data. Knowing how often patients download data from their devices and review them on their own at home may help direct device education efforts and the way this information is presented to patients.

In this cross-sectional study of one adult and one pediatric diabetes clinic, we examined the frequency of patient download and retrospective review of device data. We identified users who routinely downloaded and reviewed data from their devices and looked for demographic, socioeconomic, and clinical factors associated with routine retrospective review of data. Finally, we took an exploratory look at the reasons why patients did not download their data. The results of this study will help us understand how patients retrospectively use information from their diabetes devices and will inform future areas and target groups for improved diabetes education.

\section{Materials and Methods}

\section{Participants}

Participants were male and female adults $\geq 18$ years with T1D and caregivers of children $<18$ years with T1D who received care at the adult or pediatric tertiary diabetes center at a single institution. T1D diagnosis was ascertained from the electronic health record. Patients with other forms of diabetes (e.g., type 2, cystic fibrosis-related, medicationinduced) were excluded.

All participants received insulin by injections using the basal-bolus method or by insulin pump; those who were not using insulin, were on basal insulin only, or were on fixeddose regimens were excluded. All were required to have an understanding of written English. Patients in our centers typically have clinic visits every $2-3$ months, with measurement of hemoglobin A1c (A1c), as per American Diabetes Association guidelines. ${ }^{13}$ Participants not seen every 2-3 months with measurement of A1c were excluded. All participants in the pediatric clinic using insulin pumps or CGM completed device use education prior to device initiation, including how to download data to home computers and upload to device manufacturers' software, websites, and/ or patient portals. Training was provided by diabetes center staff and/or by a device company trainer. Teaching on downloading data was done on an individual basis in the adult clinic. Any hardware necessary for downloading was either provided with the device or was freely available to patients from the manufacturers. Potential participants were recruited by consecutive sampling at routine clinic visits. After providing informed consent, participants completed an electronic cross-sectional survey in the clinic.

The protocol and procedures were approved by the Institutional Review Board at the University of California San Francisco.

\section{Measurements}

Participants answered questions about use of diabetes devices, the frequency of BGM use, pump, and/or CGM data download, and how often they reviewed the downloaded data at home. A participant was considered a "Routine Downloader" of a device if he or she downloaded data from that device at least once between routine clinic visits every 3 months, which was four or more times in the past year. A Routine Downloader was also considered to be a "Routine Reviewer" of data from a particular device if he or she retrospectively reviewed the data from that device at least "most of the time" he or she downloaded (given the choices of "Never," "Some of the time," "Most of the time," and "Every time I downloaded").

Participants provided demographic (age, sex, race/ethnicity), socioeconomic (insurance, highest level of education of the adult patient or caregiver of a child), and clinical (time since diagnosis, devices used) information on the survey. The A1c from that clinic visit, or from another measurement within 1 month of the visit, was obtained from the electronic health record. A1c was obtained by point-of-care testing or laboratory draw. Laboratory measurement was by the BioRad (Hercules, CA) Variant ${ }^{\mathrm{TM}}$ II Turbo 2.0 and the Bio-Rad D-10 high-performance liquid chromatography systems, and point-of-care testing A1c was measured by the DCA Vantage $^{\text {TM }}$ analyzer from Siemens (Malvern, PA). The DCA Vantage analyzer has exhibited intra- and interassay coefficients of variation lower than $2.6 \%$ and $4 \%$, respectively, and correlates with the comparison high-performance liquid chromatography method $\left(r^{2}=0.9776\right) .{ }^{25}$ 


\section{Statistical analysis}

Data from adults and data from caregivers of children were analyzed separately. Frequencies of downloading at least once in the past year, of being a "Routine Downloader," and of being a "Routine Reviewer" of data from each device were reported as proportions of all users of that device, based on self-report. If a participant was a "Routine Reviewer" of data from one or more devices (BGM, pump, or CGM device), he or she was considered to be a "Routine Reviewer" of one or more devices in further analysis. Descriptive statistics ( $t$ tests for continuous variables and $\chi^{2}$ tests for dichotomous variables) were used to compare Routine Reviewers of data from one or more devices with those who were not Routine Reviewers. Multivariate logistic regression was used to look for associations of demographic, socioeconomic, and clinical factors with Routine Reviewer status. Linear regression was used to look for the association between being a Routine Reviewer of data from one or more devices with A1c, controlling for possible confounding factors. All statistical analyses were performed using Stata version 12.1 software (StataCorp, College Station, TX). For all statistical tests, significance was set to $\alpha=0.05$.

\section{Results}

\section{Participant characteristics}

In total, 340 participants completed the survey (155 adults $\geq 18$ years with T1D and 185 caregivers of children with T1D). The youngest was 1.3 years, and the oldest was 83.4 years. The study population had a median age of 17.2 years (interquartile range, 12.0, 26.5 years) and had similar demographics to other T1D patient populations, ${ }^{26}$ with $52 \%$ males, $22 \%$ ethnic minorities, $59 \%$ with at least a college degree, and $79 \%$ with private insurance. The proportions of participants using pumps (73\%) and CGM (32\%) were relatively high compared with a national registry. ${ }^{26}$ Characteristics of all participants are shown in Table 1.

\section{Frequency of participants who downloaded and reviewed data from diabetes devices}

Only $31 \%$ of adults and $56 \%$ of caregivers of children reported downloading data from one or more diabetes devices at home at least once in the past year (Fig. 1A and E). For adult patients, a greater proportion of those who used CGM downloaded their CGM data (49\%), compared with BGM (22\%) and pump (28\%) users (Fig. 1B-D). For caregivers of children, pump users were more likely to ever download their data from their pumps (61\%), compared with users of BGMs $(38 \%)$ or CGM $(43 \%)$ (Fig. $1 \mathrm{~F}-\mathrm{H})$.

"Routine Downloaders" were those who downloaded data from their device at least once between quarterly clinic visits, or four or more times in the past year. Only $20 \%$ of adults and $40 \%$ of caregivers were Routine Downloaders from one or more devices (Fig. 1A and E). A larger proportion of adult CGM users were Routine Downloaders of CGM data (40\%) than BGM (12\%) or pump (16\%) users (Fig. 1B-D), and larger proportions of caregivers of children using pumps were Routine Downloaders (43\%) compared with BGM (28\%) and CGM (29\%) users (Fig. 1F-H).

Routine Downloaders who also reviewed their device data the majority of the time they downloaded were defined as "'Routine Reviewers." Overall, only $12 \%$ of adults and $27 \%$
Table 1. Participant Characteristics

\begin{tabular}{|c|c|c|}
\hline & $\begin{array}{l}\text { Adults } \\
(\mathrm{n}=155)\end{array}$ & $\begin{array}{l}\text { Children } \\
(\mathrm{n}=185)\end{array}$ \\
\hline Mean age (years) & $34.5 \pm 16.4$ & $11.9 \pm 4.0$ \\
\hline Median age (years) & $29.5(20.2,44.4)$ & $12.5(9.0,15.1)$ \\
\hline Sex (\% male) & $50 \%$ & $54 \%$ \\
\hline Ethnicity (\% minority status) & $24 \%$ & $20 \%$ \\
\hline $\begin{array}{l}\text { White, not of Hispanic } \\
\text { origin }(\%)\end{array}$ & $66 \%$ & $69 \%$ \\
\hline $\begin{array}{l}\text { Black/African } \\
\text { American }(\%)\end{array}$ & $6 \%$ & $4 \%$ \\
\hline Hispanic/Latino & $10 \%$ & $7 \%$ \\
\hline Asian/Pacific Islander (\%) & $8 \%$ & $6 \%$ \\
\hline Other/mixed ethnicity (\%) & $6 \%$ & $11 \%$ \\
\hline $\begin{array}{l}\text { Education level (\% with } \\
\text { at least college degree) }\end{array}$ & $49 \%$ & $67 \%$ \\
\hline $\begin{array}{l}\text { Insurance status (\% with } \\
\text { private insurance) }\end{array}$ & $77 \%$ & $80 \%$ \\
\hline $\begin{array}{l}\text { Mean duration of type } 1 \\
\text { diabetes (years) }\end{array}$ & $18.5 \pm 13.5$ & $4.9 \pm 3.7$ \\
\hline Mean A1c (\%) & $8.0 \pm 1.5$ & $8.4 \pm 1.6$ \\
\hline Using blood glucose meter ${ }^{b}$ & $97 \%$ & $97 \%$ \\
\hline Using an insulin pump ${ }^{\mathrm{b}}$ & $68 \%$ & $77 \%$ \\
\hline $\begin{array}{l}\text { Using continuous } \\
\text { glucose monitoring }\end{array}$ & $28 \%$ & $36 \%$ \\
\hline
\end{tabular}

Data are mean \pm SD values, median values (interquartile range), or frequencies, as indicated. The following were missing data: ethnicity, $n=10$; education level, $n=13$; insurance status, $n=19$; duration of type 1 diabetes, $n=5$.

${ }^{a}$ For children, education level of caregiver.

${ }^{\mathrm{b}}$ Use of a blood glucose meter, insulin pump, or continuous glucose monitoring was not mutually exclusive.

A1c, hemoglobin A1c.

of caregivers were Routine Reviewers of data from one or more devices (Fig. 1A and E). There were larger proportions of Routine Reviewers among adult users of CGM (28\% vs. $5 \%$ of BGM users and $7 \%$ of pump users) and among caregivers of children using pumps (27\% vs. $19 \%$ of BGM users and $22 \%$ of CGM users) (Fig. 1B-D and F-H).

\section{Characteristics of Routine Reviewers \\ of at least one device}

Characteristics of adults and children of caregivers who were Routine Reviewers of data from one or more devices are shown in Table 2. In both groups, the average A1c was lower in Routine Reviewers compared with non-Routine Reviewers $(7.2 \pm 1.0 \%$ vs. $8.1 \pm 1.6 \%[P=0.03]$ in adults and $7.8 \pm 1.4 \%$ vs. $8.6 \pm 1.7 \%[P=0.001]$ in children). Mean age and T1D duration were significantly different in the Routine Reviewer groups compared with the non-Routine Reviewers; however, the direction of the relationship was opposite in the two groups. Among adults, Routine Reviewers were older (44.9 \pm 13.1 years) than non-Routine Reviewers $(32.9 \pm 16.2$ years) $(P=0.003)$, whereas among caregivers, the children of Routine Reviewers were younger $(10.8 \pm 4.0$ years) than those of non-Routine Reviewers $(12.3 \pm 3.9$ years $)(P=0.02)$. Similarly, adult Routine Reviewers had diabetes longer compared with non-Routine Reviewers $(28.7 \pm 5.5$ vs. $17.2 \pm 12.7$ years; $P=0.0006)$, whereas caregivers who were Routine Reviewers had children with diabetes for less time compared with non-Routine Reviewers $(3.7 \pm 3.1$ vs. $5.5 \pm 3.8$ years; $P=0.005)$. There were no statistically significant differences in the proportion 

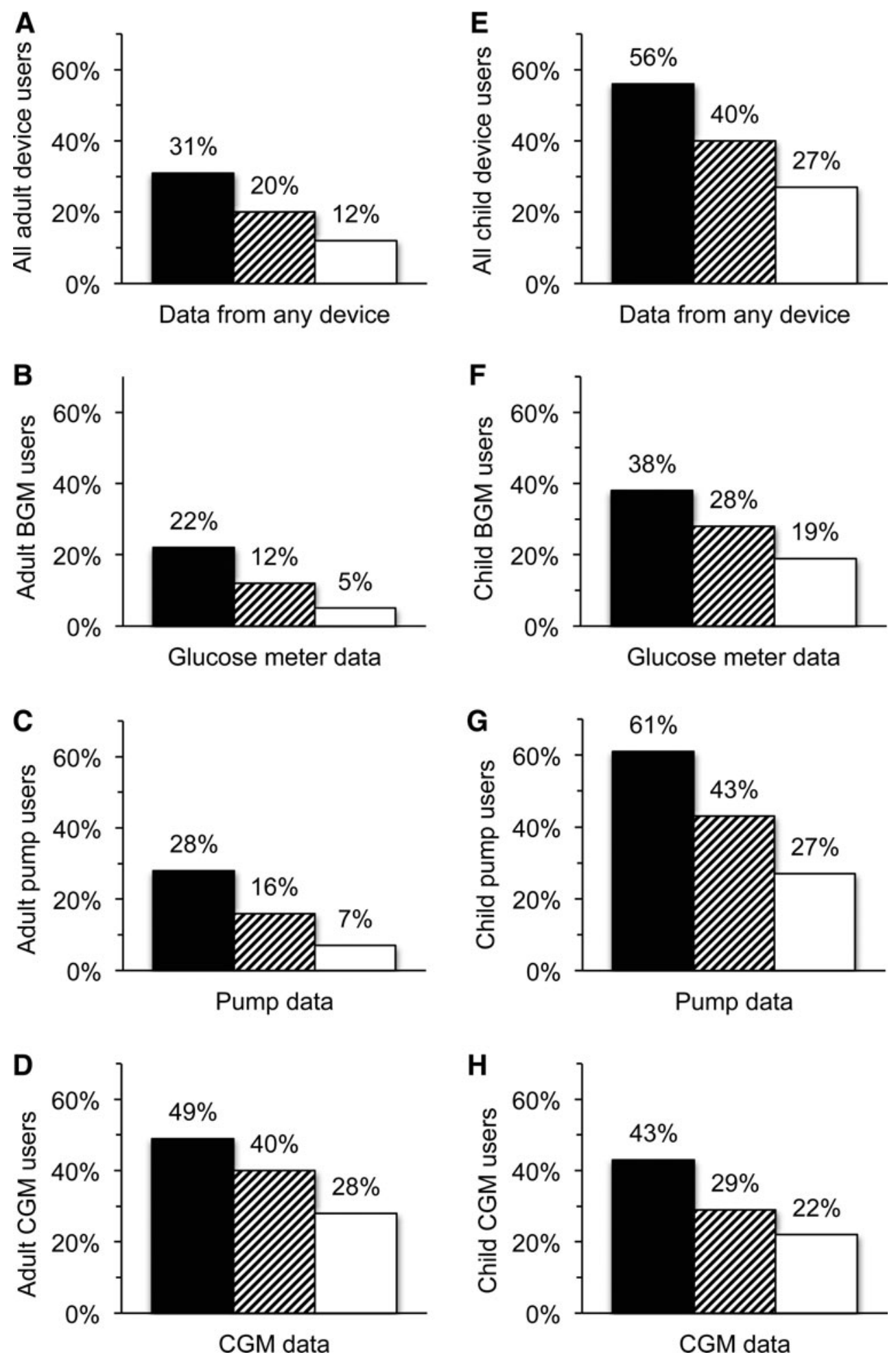

FIG. 1. Frequency of patients who download and review their device data: (A) all adult device users $(n=154)$; (B) adult blood glucose meter (BGM) users $(n=149)$; (C) adult pump users $(n=104)$; (D) adult continuous glucose monitoring $(\mathrm{CGM})$ users $(n=43)$; $(\mathbf{E})$ all child device users $(n=182)$; $(\mathbf{F})$ child BGM users $(n=175)$; $(\mathbf{G})$ child pump users $(n=137)$; and $(\mathbf{H})$ child CGM users $(n=65)$. Device users may not be mutually exclusive. Usage was classified as ever download (black bars), Routine Downloader (striped bars), or Routine Reviewer (white bars). 
Table 2. Comparisons Between Routine Reviewers and Non-Routine Reviewers of at Least One Device

\begin{tabular}{|c|c|c|c|}
\hline Participants, characteristic & Routine Reviewers & Non-Reviewers & $\mathrm{P}$ \\
\hline \multicolumn{4}{|l|}{ Adults } \\
\hline Number of participants & 18 & 136 & \\
\hline Mean age (years) & $44.9 \pm 13.1$ & $32.9 \pm 16.2$ & 0.003 \\
\hline Sex $(\%$ male $)$ & $61 \%$ & $48 \%$ & 0.29 \\
\hline Ethnicity (\% minority status) & $11 \%$ & $27 \%$ & 0.15 \\
\hline Education level (\% with at least college degree) $)^{\mathrm{a}}$ & $83 \%$ & $66 \%$ & 0.13 \\
\hline Insurance status (\% with non-private insurance) & $11 \%$ & $25 \%$ & 0.18 \\
\hline Mean duration of type 1 diabetes (years) & $28.7 \pm 15.5$ & $17.2 \pm 12.7$ & 0.0006 \\
\hline Mean A1c $(\%)$ & $7.2 \pm 1.0$ & $8.1 \pm 1.6$ & 0.03 \\
\hline \multicolumn{4}{|l|}{ Children } \\
\hline Number of participants & 50 & 132 & \\
\hline Mean age of child (years) & $10.8 \pm 4.0$ & $12.3 \pm 3.9$ & 0.02 \\
\hline Sex of child ( $\%$ male $)$ & $58 \%$ & $53 \%$ & 0.55 \\
\hline Ethnicity (\% minority status) & $14 \%$ & $21 \%$ & 0.33 \\
\hline Caregiver education (\% with at least college degree) & $75 \%$ & $64 \%$ & 0.17 \\
\hline Insurance status (\% with non-private insurance) & $11 \%$ & $22 \%$ & 0.10 \\
\hline Mean duration of type 1 diabetes (years) & $3.7 \pm 3.1$ & $5.5 \pm 3.8$ & 0.005 \\
\hline Mean A1c $(\%)$ & $7.8 \pm 1.4$ & $8.6 \pm 1.7$ & 0.001 \\
\hline
\end{tabular}

of Routine Reviewers who were male versus female, ethnic minorities, had at least a college degree, or private insurance, compared with non-Routine Reviewers (Table 2). However, there were trends toward smaller proportions of ethnic minorities, larger proportions with at least a college degree, and lower proportions without private insurance in the Routine Reviewer groups.

To identify factors associated with Routine Reviewer status while controlling for possible confounders, multivariate logistic regression was used with age and T1D duration in separate models because of the possibility of collinearity. Among adults, both older age (odds ratio $=1.04$; 95\% confidence interval, 1.01, 1.08; $P=0.02)$ and longer T1D duration (odds ratio $=1.05 ; 95 \%$ confidence interval, 1.01 , $1.09 ; P=0.01)$ remained associated with Routine Reviewer status, after controlling for sex, minority status, education, and insurance status. For every 10-year increase in age, there was 1.5 (95\% confidence interval, 1.1, 2.1) times increased odds of being a Routine Reviewer, and for every 10 years since diagnosis, there was 1.7 (95\% confidence interval, 1.2, 2.4) times increased odds of being a Routine Reviewer. For caregivers, age of the child and T1D duration were not significantly associated with the caregiver being a Routine Reviewer in adjusted analysis. However, there were trends toward caregivers of younger children (odds ratio $=0.93$; 95\% confidence interval, $0.85,1.0 ; P=0.13$ ) and of children with shorter T1D diagnosis (odds ratio $=0.89 ; 95 \%$ confidence interval, $0.79,1.0 ; P=0.05$ ) being associated with Routine Reviewer status. Separate multivariate models showed no associations of being a Routine Reviewer with A1c in either group (data not shown).

\section{Preliminary assessment of obstacles to downloading and reviewing device data}

Participants were asked to choose from a list of reasons or provide other explanations why they did not regularly down- load data from their devices. Responses were not mutually exclusive. The responses were grouped into eight categories, in addition to reasons specific to BGM or CGM data (Table 3). Major reasons included the following: lack of proper equipment; lack of awareness that downloading data was possible or recommended; lack of knowledge of how to download the data; lack of time, motivation, or interest; technical reasons; lack of understanding or dislike of the software; use of alternative methods to view data; and being a new user. Common reasons for not downloading data from BGMs included preference for using pump and CGM data and the fact that the BGM data are often transferred to the pump manually or automatically. A few CGM users commented that they did not download CGM data because they downloaded data from their pumps, even though CGM and pump downloads show different, but complementary, information.

\section{Discussion}

Although using retrospective data from diabetes devices is important for insulin adjustment in T1D, which is recommended between clinic visits, few data exist describing how often patients acquire and review this information. In this study, we show that fewer than one-third of adults and about half of caregivers of children with T1D reported ever downloading data from at least one of their diabetes devices in the past year; the number of those who did this routinely was even less. This was at a diabetes center where use of devices is higher than other reports, suggesting that in a population with a relatively high rate of technology use, downloading data is not a priority. Even fewer still were the numbers of users who reviewed downloaded information, with only $12 \%$ of adults and $27 \%$ of caregivers of children doing this routinely. The finding that a minority of patients download data from their devices is in agreement with prior studies. ${ }^{12,23,24}$ To our knowledge, this is the first study to report the frequency at which patients retrospectively review their downloaded 
Table 3. Reasons for Not Downloading Data from Devices

\begin{tabular}{|c|c|c|}
\hline Major categories & $\begin{array}{l}\text { Multiple choice } \\
\text { options given }\end{array}$ & Other participant responses \\
\hline $\begin{array}{l}\text { Lack of proper } \\
\text { equipment }\end{array}$ & $\begin{array}{l}\text { - I don't have } \\
\text { a computer. }\end{array}$ & $\begin{array}{l}\text { - "I don't have the software or the cord } \\
\text { to connect the meter." } \\
\text { - "I wasn't given the cord." } \\
\text { - "Lost the connector." } \\
\text { - "No software available." }\end{array}$ \\
\hline $\begin{array}{l}\text { Unaware that downloading } \\
\text { data was possible } \\
\text { or recommended }\end{array}$ & & $\begin{array}{l}\text { - "Not requested." } \\
\text { - "I didn't know I could." } \\
\text { - "Doctor didn't ask.", } \\
\text { - "Didn't know that I could do that.", }\end{array}$ \\
\hline $\begin{array}{l}\text { Don't know how } \\
\text { to download data }\end{array}$ & $\begin{array}{l}\text { - I don't know how } \\
\text { to download the device. }\end{array}$ & $\begin{array}{l}\text { - "Misplaced information." } \\
\text { - "Not comfortable downloading." }\end{array}$ \\
\hline $\begin{array}{l}\text { Lack of time, motivation, } \\
\text { or interest }\end{array}$ & $\begin{array}{l}\text { - I didn't have time. } \\
\text { - I forgot. } \\
\text { - I don't need the } \\
\text { information from } \\
\text { the download. }\end{array}$ & $\begin{array}{l}\text { - "Lots of time." } \\
\text { - "Not interested in using the software." } \\
\text { - "Lazy.", } \\
\text { - "I didn't have the focus.", } \\
\text { - "Forgot to even load the software.", }\end{array}$ \\
\hline Technical reasons & $\begin{array}{l}\text { - The software program } \\
\text { did not work. } \\
\text { - The software is not } \\
\text { compatible with } \\
\text { my computer. }\end{array}$ & $\begin{array}{l}\text { - "Does not support Windows 8." } \\
\text { - "Incompatible with Mac." } \\
\text { - "Need to set up a new password.", } \\
\text { - "Technology is incomplete." }\end{array}$ \\
\hline $\begin{array}{l}\text { Don't understand } \\
\text { or like the software }\end{array}$ & $\begin{array}{l}\text { - I don't know what } \\
\text { to do with the } \\
\text { information. }\end{array}$ & $\begin{array}{l}\text { - "Awkward/slow interface." } \\
\text { - "Device readings cannot be trusted", } \\
\text { - "Graphs are too complicated and hard } \\
\text { to make sense of." } \\
\text { - "Software is clumsy." } \\
\text { - "The graphs are hard to read, overwhelming.", }\end{array}$ \\
\hline Alternative methods & & $\begin{array}{l}\text { - "I can write it down." } \\
\text { - "I write everything down and look at it constantly.", } \\
\text { - "Use a paper log." }\end{array}$ \\
\hline New user & & $\begin{array}{l}\text { - "6 months into diagnosis, but ideally see the benefit." } \\
\text { - "Brand new to CGM" } \\
\text { - "Just did a trial week" } \\
\text { - "Just got new meter last week", } \\
\text { - "Just started using it" }\end{array}$ \\
\hline BGM-specific reasons & & $\begin{array}{l}\text { - "CGM gives better data." } \\
\text { - "Download pump if need info.", } \\
\text { - "Have a CGM." } \\
\text { - "The numbers connect to my pump." } \\
\text { - "We enter blood glucose info into pump." } \\
\text { - "We use the pump upload instead." }\end{array}$ \\
\hline CGM-specific reasons & & $\begin{array}{l}\text { - "I only download from pump." } \\
\text { - "We upload [the pump] instead." }\end{array}$ \\
\hline
\end{tabular}

BGM, blood glucose meter; CGM, continuous glucose monitoring.

data. The results suggest that the majority of patients are not actively using these retrospective features of their devices.

It is of interest that adult users of CGM and caregivers of children using pumps downloaded and reviewed information from these devices more regularly than did users of other devices. This suggests that adult patients find data from CGM more useful than that collected from other devices, or that CGM software may be easier to use. We acknowledge that increased frequency of CGM download and review may represent a selection bias that cannot be addressed by this crosssectional study; adults who choose to use CGM may be more likely than the general T1D population to review their data. For caregivers, users of pumps more routinely downloaded and reviewed pump data, suggesting that pump downloads are more useful for those managing diabetes in their children. One factor that might influence this difference between adult patients and caregivers is that our pediatric providers routinely download and review device data with families at each clinic visit, and the pediatric practice encourages caregivers to download device data at home and send them to providers to review between visits. In contrast, the adult practice does not routinely download device data in the clinic, but instead asks patients to keep paper logs or bring hardcopies of the downloads to visits. Providers in the adult practice also do not regularly review patient-generated downloads between visits, and patients are expected to review data on their own. This difference in clinical 
practice is not atypical of pediatric compared with adult clin$\mathrm{ics}^{27}$ and may explain why frequency of downloading and reviewing data was higher overall among caregivers in the pediatric practice. It also suggests that if providers actively download and use the data in the clinic, this may influence patients to independently adopt these practices. Further studies are required to test this hypothesis.

In adjusted analysis, the relationship between age and T1D duration and the likelihood of routine data review differed between adults and caregivers of children. Older adults, and those adults who had diabetes longer, were more likely to be Routine Reviewers of device data. Data review can be considered a marker of engagement in self-care. Our finding that this behavior increases with age is consistent with the fact that self-care improves as emerging adults reach later stages of adulthood. ${ }^{27}$ It also parallels the improvement in A1c that occurs with age after adolescence, ${ }^{26}$ suggesting that review of data, increased selfcare, and more optimal A1c may be related. In contrast, there was a trend that caregivers of younger children and of those with a newer diagnosis were more likely to review device data, suggesting that caregivers of younger children, or of those with a more recent diagnosis, interact with data more often. This agrees with other findings that parental involvement in diabetes management declines as a child progresses through adolescence. ${ }^{28,29}$ These findings in both groups indicate that data download and review are most often neglected in adolescents and young adults.

Although unadjusted analysis showed that those who more frequently reviewed device data had lower mean A1c, we did not detect a significant association between those who were Routine Reviewers of their data and A1c after adjustment. This may be because our study was not powered to detect these differences, and a larger sample size and/or prospective study may be necessary to evaluate an association between patient self-review of data and glycemic control. In addition, this study did not explore how patients used device data after they reviewed them; it is not known if they sent the data to a provider, made changes to their insulin plans on their own, or understood or did anything with the information from their devices. It is possible that simply asking patients to download and review their data, without knowing how they are interpreting and using it, does not have an impact on A1c. Further qualitative studies are necessary to determine what patients understand about their data downloads, given the current tools available, and what they do with the information. Others have enforced the need for continuing education and training in interpreting and applying device data. ${ }^{10,30}$ Better tools, resources, and education regarding use of diabetes data may be necessary in order for self-review to influence glycemic control.

The need for better tools to obtain diabetes data was suggested by our preliminary look at obstacles to downloading and reviewing data. Although some participants felt that there was no need to review the data, many reasons reflected a lack of knowledge or proper equipment, technical difficulties, or frustration with the available hardware and software applications. Looking forward, providers should educate patients on the process of data download, when and how it should be done, and how to interpret and use the information. These results also suggest the need for more seamless, less timeintensive methods of data acquisition from devices and for easily understandable forms of data visualization.

We recognize the limitations of our study. These include its cross-sectional nature and the use of self-reported data.
However, in cases of self-reported "favorable" behavior, there is a tendency to overreport. ${ }^{31,32}$ Also, patients may have considered any downloading events immediately prior to their clinic visit (for use by the diabetes provider) in their frequency of downloading data at home. If this is true, the actual frequency of independent download and review of data between clinic visits may be even lower than reported. We acknowledge that our definition of "routine" download and review was conservative, knowing that other studies asked patients to download data weekly or monthly ${ }^{12,24}$ or considered weekly download to be a target. ${ }^{23,26}$ The number of participants who downloaded or reviewed data weekly would be smaller by these more stringent definitions. As mentioned, we had a high percentage of device users, suggesting an affinity or comfort with technology in our population that might not be present in all general T1D populations. This might suggest that the frequency of downloading and reviewing data in a population that is more technology-averse could be even lower. Finally, although our survey inquired about data review, we do not specifically know the actions that patients took after downloading and reviewing their data. Further studies will enable us to gain a better understanding of how patients review data on their own and if any of these actions is associated with improved glycemic control.

In summary, a minority of patients with T1D and caregivers of children with T1D routinely retrospectively reviews past data from diabetes devices. Future research will determine if patient self-review influences glycemic control, and effort should be made to help patients better understand and use their data. Regardless of how patients use data on their own, because providers can use device data to adjust insulin regimens, patients should be educated on how to acquire and communicate their data to their providers for review between visits. In particular, young adults and caregivers of adolescents review data less routinely and should be specifically targeted for educational efforts. Improvements in device hardware and software could facilitate the data review process, making data collection, visualization, and interpretation easier in the future.

\section{Acknowledgments}

We thank the patients and staff at the Madison Clinic for Pediatric Diabetes at UCSF Benioff Children's Hospital and the Justine K. Schreyer Adult Diabetes Care Center at UCSF Medical Center for their support, cooperation, and participation in this study. J.C.W. is supported by K12 Physician Scientist Award DK094726 from the National Institutes of Health (K12 in Diabetes [KIDS]).

\section{Author Disclosure Statement}

J.C.W., A.B.N., and M.S. declare no competing financial interests exist. S.A. consults for and owns publicly traded shares in Dexcom and Tandem Diabetes.

\section{References}

1. The Diabetes Control and Complications Trial Research Group: The effect of intensive treatment of diabetes on the development and progression of long-term complications in insulin-dependent diabetes mellitus. N Engl J Med 1993; 329:977-986. 
2. Nathan DM, Cleary PA, Backlund J-YC, et al.: Intensive diabetes treatment and cardiovascular disease in patients with type 1 diabetes. N Engl J Med 2005;353:2643-2653.

3. Nathan DM, Zinman B, Cleary PA, et al.: Modern-day clinical course of type 1 diabetes mellitus after 30 years' duration: the Diabetes Control and Complications Trial/Epidemiology of Diabetes Interventions and Complications and Pittsburgh Epidemiology of Diabetes Complications experience (19832005). Arch Intern Med 2009;169:1307-1316.

4. Training in flexible, intensive insulin management to enable dietary freedom in people with type 1 diabetes: Dose Adjustment for Normal Eating (DAFNE) randomised controlled trial. BMJ 2002;325:746.

5. Lowe J, Linjawi S, Mensch M, et al.: Flexible eating and flexible insulin dosing in patients with diabetes: results of an intensive self-management course. Diabetes Res Clin Pract 2008;80:439-443.

6. Franc S, Dardari D, Boucherie B, et al.: Real-life application and validation of flexible intensive insulin-therapy algorithms in type 1 diabetes patients. Diabetes Metab 2009; 35:463-468.

7. Amiel SA: Type 1 diabetes: treatment without tears? Diabetologia 2005;48:1963-1964.

8. Lawton J, Rankin D, Cooke D, et al.: Patients' experiences of adjusting insulin doses when implementing flexible intensive insulin therapy: a longitudinal, qualitative investigation. Diabetes Res Clin Pract 2012;98:236-242.

9. Shalitin S, Phillip M: The role of new technologies in treating children and adolescents with type 1 diabetes mellitus. Pediatr Diabetes 2007;8(Suppl 6):72-79.

10. Rubin RR, Borgman SK, Sulik BT: Crossing the technology divide: practical strategies for transitioning patients from multiple daily insulin injections to sensor-augmented pump therapy. Diabetes Educ 2011;37(Suppl 1):5S-18S; quiz 19S-20S.

11. Welsh JB, Myers SJ, Uhrinak AN, et al.: User acceptability and perceived benefits of new reports in CareLink Pro 3.0 Therapy Management Software for Diabetes. J Diabetes Sci Technol 2012;6:481-482.

12. Shalitin S, Ben-Ari T, Yackobovitch-Gavan M, et al.: Using the Internet-based upload blood glucose monitoring and therapy management system in patients with type 1 diabetes. Acta Diabetol 2014;51:247-256.

13. American Diabetes Association: Standards of medical care in diabetes-2014. Diabetes Care 2014;37(Suppl 1):S14-S80.

14. Pihoker C, Forsander G, Fantahun B, et al.: The delivery of ambulatory diabetes care to children and adolescents with diabetes. Pediatr Diabetes 2014;15(Suppl 20):86-101.

15. Meade LT, Rushton WE: Optimizing insulin pump therapy: a quality improvement project. Diabetes Educ 2013;39:841-847.

16. Nardacci EA, Bode BW, Hirsch IB: Individualizing care for the many: the evolving role of professional continuous glucose monitoring systems in clinical practice. Diabetes Educ 2010;36(Suppl 1):4S-19S; quiz 20S-21S.

17. Bashan E, Herman WH, Hodish I: Are glucose readings sufficient to adjust insulin dosage? Diabetes Technol Ther 2011;13:85-92.

18. Bashan E, Hodish I: Frequent insulin dosage adjustments based on glucose readings alone are sufficient for a safe and effective therapy. J Diabetes Complications 2012;26:230-236.

19. Bode BW, Gross TM, Thornton KR, Mastrototaro JJ: Continuous glucose monitoring used to adjust diabetes therapy improves glycosylated hemoglobin: a pilot study. Diabetes Res Clin Pract 1999;46:183-190.
20. Tanenberg R, Bode B, Lane W, et al.: Use of the Continuous Glucose Monitoring System to guide therapy in patients with insulin-treated diabetes: a randomized controlled trial. Mayo Clin Proc 2004;79:1521-1526.

21. Mauras N, Fox L, Englert K, et al.: Continuous glucose monitoring in type 1 diabetes. Endocrine 2013;43:41-50.

22. Buckingham B, Xing D, Weinzimer S, et al.: Use of the DirecNet Applied Treatment Algorithm (DATA) for diabetes management with a real-time continuous glucose monitor (the FreeStyle Navigator). Pediatr Diabetes 2008; 9:142-147.

23. Wong JC, Foster NC, Maahs DM, et al.: Real-time continuous glucose monitoring among participants in the T1D Exchange Clinic Registry. Diabetes Care 2014;37:2702-2709.

24. Corriveau EA, Durso PJ, Kaufman ED, et al.: Effect of Carelink, an internet-based insulin pump monitoring system, on glycemic control in rural and urban children with type 1 diabetes mellitus. Pediatr Diabetes 2008;9:360-366.

25. Szymezak J, Leroy N, Lavalard E, et al.: Evaluation of the DCA Vantage analyzer for HbA 1c assay. Clin Chem Lab Med 2008;46:1195-1198.

26. Beck RW, Tamborlane WV, Bergenstal RM, et al:: The T1D Exchange clinic registry. J Clin Endocrinol Metab 2012;97:4383-4389.

27. Peters A, Laffel L, American Diabetes Association Transitions Working Group: Diabetes care for emerging adults: recommendations for transition from pediatric to adult diabetes care systems: a position statement of the American Diabetes Association, with representation by the American College of Osteopathic Family Physicians, the American Academy of Pediatrics, the American Association of Clinical Endocrinologists, the American Osteopathic Association, the Centers for Disease Control and Prevention, Children with Diabetes, The Endocrine Society, the International Society for Pediatric and Adolescent Diabetes, Juvenile Diabetes Research Foundation International, the National Diabetes Education Program, and the Pediatric Endocrine Society (formerly Lawson Wilkins Pediatric Endocrine Society). Diabetes Care 2011;34:2477-2485.

28. Anderson B, Ho J, Brackett J, et al.: Parental involvement in diabetes management tasks: relationships to blood glucose monitoring adherence and metabolic control in young adolescents with insulin-dependent diabetes mellitus. J Pediatr 1997; 130:257-265.

29. King PS, Berg CA, Butner J, et al.: Longitudinal trajectories of parental involvement in Type 1 diabetes and adolescents' adherence. Health Psychol 2014;33:424-432.

30. Effectiveness of continuous glucose monitoring in a clinical care environment: evidence from the Juvenile Diabetes Research Foundation continuous glucose monitoring (JDRF-CGM) trial. Diabetes Care 2010;33:17-22.

31. Edwards AL: The Social Desirability Variable in Personality Assessment and Research. New York: Dryden, 1957.

32. Nunnally JC: Psychometric Theory, 2nd ed. New York: McGraw-Hill, 1978.

Address correspondence to: Jenise C. Wong, MD PhD Division of Endocrinology Department of Pediatrics $55016^{\text {th }}$ Street, Fourth Floor, Box 0434 San Francisco, CA 94143-0434

E-mail: Jenise.Wong@ucsf.edu 